Шинкевич Елена Святославовна, А-р техн. наук, профессор, ОАесская государственная академия строительства и архитектуры (г. ОАесса, Украина)

ЛинникАмитрий Сергеевич, научный сотрудник, ОАесская государственная академия строительства и архитектуры (г. ОАесса, Украина)

Закаблук Станислав Станиславович, руководитель научно-технического отАела строительной компании ТММ (г. Киев, Украина)

\title{
АРБОЛИТОБЕТОН ПОНИЖЕННОЙ ПЛОТНОСТИ НА КОМПОЗИЦИОННОМ ГИПСОВОМ ВЯЖУЩЕМ
}

(C) РУП “Институт БелНИИС", 2019

Institute BeINIIS RUE, 2019

\section{АННОТАЦИЯ}

В статье показана актуальность использования отходов промышленности и сельского хозяйства в технологии получения композиционных материалов. Сделан краткий обзор специфических особенностей целлюлозосодержащих заполнителей растительного происхождения для арболитобетона. Проанализированы композиты на основе целлюлозосодержащего заполнителя с различными видами вяжущего: гипсо- цементно-пуциоланового, цементного, известкового и известьсодержащего, магнезиального, на основе жидкого стекла. Отражены достоинства и недостатки каждо-

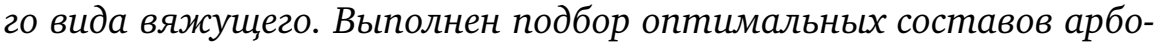
литобетона на композиционном гипсовом вяжущем пониженной плотности. Исследованы физико-механические свойства органического заполнителя. Проведен анализ возможности повышения биостойкости арболитобетона нанодобавкой высокоактивного пирогенного микрокремнезема, модифицированного соединениями металлов. Показано, что высокоразвитая поверхность и особенное строение пирогенного кремнезема позволяют использовать его в качестве матрищы для формирования наноразмерных структур. Представлены результаты исследований арболитобетона с 
добавкой высокоактивного пирогенного микрокремнезема, модифицированного соединениями металлов, на антимикробную активность. Особенность разработанного авторами арболитобетона - использование композиционного гипсового вяжущего (КГВ) с повышенной водостойкостью. На основе методов математического моделирования выполнена серия экспериментов по подбору и оптимизации состава арболитобетона по показателям прочности, плотности, водостойкости с учетом состава композиционного гипсового вяжущего, фракционного состава костры и соотношения компонентов в системе «вяжущее - органический заполнитель». Оптимальные составы обеспечивают класс прочно-

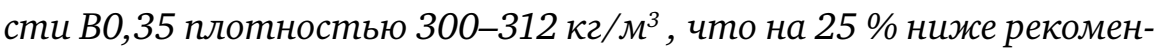
дованных ДСТУ БВ.2.7-271:2011 «Арболит и изделия из него» значений плотности для арболитобетона, удовлетворяющего классу по прочности В0,35. Таким образом, применение композиционного гипсового вяжущего позволит снизить плотность аролитобетона без ухудшения других его эксплуатационных свойств.

Ключевые слова: экоматериал, композит, гипс, арболитобетон, модель, оптимизация, фракция, состав.

Для цитирования: Шинкевич, Е. С. Арболитобетон пониженной плотности на композиционном гипсовом вяжущем / Е. С. Шинкевич, Д. С. Линник, С. С. Закаблук // Проблемы современного бетона и железобетона : сб. науч. тр. / Ин-т БелНИИС; редкол.: О. Н. Лешкевич [и др.]. - Минск, 2019. - Вып. 11. - С. 331347. https://doi.org/10.35579/2076-6033-2019-11-20

Elena Shinkevich, DSc in Engineering Science, Professor, Odessa State Academy of Civil Engineering and Architecture (Odessa, Ukraine)

Dmitriy Linnik, Researcher, Odessa State Academy of Civil Engineering and Architecture (Odessa, Ukraine)

Stanislav Zakabluk, Head of the Scientific Technical Department of the construction company TMM (Kiev, Ukraine) 


\section{PAPERCRETE OF REDUCED DENSITY AT COMPOSITIONAL GYPSUM TENSION}

\section{ABSTRACT}

The article shows the relevance of the use of ind ustrial and agricultural waste in the technology of composite materials. A brief review of the specific features of cellulose-containing fillers of plant origin for wood concrete is made. Composites based on cellulose-containing aggregate with various types of binder: gypsum-cement-pozzolan, cement, lime, and lime containing, magnesian, based on liquid glass were analyzed. The advantages and disadvantages of each type of binder are reflected. The selection of optimal compositions of wood concrete on composite gypsum binder with low density is made. The physicomechanical properties of the organic filler are investigated. The analysis of the possibility of increasing the biological resistance of papercrete with a nano-additive of highly active pyrogenic microsilica modified with metal compounds was carried out. It is shown that the highly developed surface and the special structure of pyrogenic silica allows its use as a matrix for the formation of nanoscale structures. The results of studies of papercrete with the addition of highly active pyrogenic microsilica modified with metal compounds on antimicrobial activity are presented. A feature of papercrete developed by the authors is the use of a composite gypsum binder (KGV) with enhanced water resistance. Based on mathematical modeling methods, a series of experiments were carried out to select and optimize the composition of wood concrete based on strength, density, water resistance, taking into account the composition of composite gypsum binder, fractional composition of fires and the ratio of components in the binder-bonfire system. Optimal formulations provide class B0.35 of strength with a density of $300-312 \mathrm{~kg} / \mathrm{m}^{3}$, which is $25 \%$ lower than the density values recommended for DSTU BV.2.7-271: 2011 "Papercrete and products from it" for papercrete that satisfies class B0.35 in strength. Thus, the use of a composite gypsum binder will reduce the density of papercrete, without compromising other performance properties.

Keywords: ecomaterial, composite, gypsum, papercrete, model, optimization, fraction, composition. 
For citation: Shinkevich E., Linnik D., Zakabluk S. Papercrete of reduced density at compositional gypsum tension. Contemporary Issues of Concrete and Reinforced Concrete: Collected Research Papers. Minsk. Institute BelNIIS. Vol. 11. 2019. pp. 331-347. https://doi. org/10.35579/2076-6033-2019-11-20 (in Russian)

\section{BВEAЕНИЕ}

Большое внимание в последние годы уделяется широкому использованию отходов промышленности и сельского хозяйства в технологии получения композиционных материалов. Особую актуальность приобрело использование отходов растительного происхождения в качестве сырья для их производства. Это позволит расширить утилизацию отходов и получить дешевое местное сырье для получения новых материалов. Такие исследования проводятся во многих странах, что обусловлено ростом дефицита древесины для производства строительных материалов и изделий. Одним из видов экоматериалов, удовлетворяющих этим требованиям, является арболит (арболитобетон) - легкий бетон на основе различных видов органических целлюлозосодержащих заполнителей (отходов древесины, соломы, костры конопли, льна и т. п.) и вяжущих $[1,2]$.

Целлюлозосодержащие заполнители растительного происхождения, включающие стебли лубяных культур (костра льна, конопли и др.), наряду с присущими им ценными свойствами, такими как малая средняя плотность, не дефицитность, хорошая смачиваемость, легкость обработки и др., имеет и отрицательные качества, которые затрудняют получение материала высокой прочности. Снижение прочности арболитобетона связано со специфическими свойствами древесного заполнителя [3]: повышенной химической активностью, значительной степенью объемных влажностных деформаций, низкой адгезией по отношению к вяжущему, резко выраженной анизотропией в разных структурных направлениях, значительной упругостью при уплотнении смеси. Степень влияния этих свойств заполнителей 
растительного происхождения на процессы структурообразования и физико-механические свойства арболитобетона различна.

Учитывая зарубежный опыт [4-7], наиболее перспективно использовать в качестве органического заполнителя костру конопли - распространенное и дешевое сырье в Украине. Применение костры конопли для производства арболита более рационально еще и потому, что фракционный состав костры, поступающей с пенькозаводов, удовлетворяет предъявляемым требованиям [8]. Вместе с тем слабо изучены вопросы производства арболитобетона на основе костры конопли с использованием композитов на основе гипсовых вяжущих, его преимущества и недостатки, физико-механические свойства, вопросы изготовления, формирования и твердения.

Цель исследования: подбор оптимальных составов арболитобетона на композиционном гипсовом вяжущем пониженной плотности.

Задача исследования: обоснование выбора компонентов вяжущего, исследование физико-механических характеристик композиционного гипсового вяжущего, исследование физико-механических свойств органического заполнителя, повышение биостойкости арболитобетона, подбор оптимальных составов арболитобетона, расчет и анализ общих закономерностей изменения свойств арболитобетона под влиянием фракционного состава органического заполнителя.

\section{МАТЕРИАЛЫ И МЕТОАЫ ИССАЕАОВАНИЙ}

В качестве компонентов вяжущего применялись: строительных гипс Г5 производства ПАО «Гипсовик», цемент пуццолановый бездобавочный производства ОАО «Евро цемент Украина» ПЦ-І-500Д0 согласно ДСТУ Б В.2.7-46:2010.

В качестве активных пуццолановых добавок для получения композиционного гипсового вяжущего применялись: высокоактивный метакаолин ТУ У 14.2-36363275-001:2009 производства ООО «Мета-Д», микрокремнезем производства Elkem AS EN 13263 - 1. 
В качестве добавки замедлителя схватывания применялся суперпластификатор Sika ViscoCrete 225 порошок VP SIA 162 (1989) и prEN 934-2, производства т. м. Sika.

Органический заполнитель костра конопли - отход канатного завода г. Харькова.

Испытания композиционных гипсовых вяжущих осуществлялись по ДСТУ Б В.2.7-187:2009, образцы испытывались на прочность в возрасте 7 сут. с последующим высушиванием до постоянной массы. Определение коэффициента размягчения осуществлялось по ТУ 21-0284757-90.

Исследуемые образцы арболитобетона на основе композиционного гипсового вяжущего изготовлялись и испытывались в возрасте 28 сут. твердения в нормальных условиях согласно ДСТУ Б В.2.7-271:2011 по показателю прочности при сжатии, определялась плотность образцов.

\section{АНААИЗ РЕЗУАЬТАТОВ ИССАЕАОВАНИЙ}

Обоснование выбора компонентов вяжущего. Исследования по подбору состава вяжущего для арболитобетона предусматривали широкий выбор вариантов вяжущих: цемент, гипс, известь, магнезиальное вяжущее, жидкое натриевое стекло [9-10]. Выбор вариантов исходил из соображений, связанных с определенными ограничениями и начальными условиями, продиктованными требованиями технологичности получения композита, затрат на исходные материалы, прогнозируемыми производственными затратами, длительностью технологического цикла получения строительных изделий из композита и т. п.

На основании проведенных поисковых исследований можно говорить о достоинствах и недостатках каждого вида вяжущего. Цемент широко используется как основа для производства арболитобетона в странах СНГ. Составы на цементном вяжущем показывают высокую прочность и стойкость к влагопеременным воздействиям, но имеют повышенную плотность и требуют обработки целлюлозного заполнителя минерализаторами. Известь широко используется при производстве арболита в странах ЕС и Северной Америки. Изделия на извести имеют низкую плотность, 
достаточную прочность. Недостаток известкового вяжущего медленный набор марочной прочности изделий. Достоинством жидкого стекла как вяжущего является то, что оно хорошо связывается с органическим заполнителем и в сочетании с добавками обеспечивает материалу с таким заполнителем необходимую биостойкость, огнестойкость и достаточную механическую прочность. На его твердение не оказывают влияния сахара и реактивные вещества, находящиеся в древесине. Однако данное вяжущее обладает высокой стоимостью. Магнезиальное вяжущее является подходящей заменой для цемента в легких композитах. Однако плотность полученных изделий довольно высокая и составляет 790-1200 кг/м³ [5-7]. Наиболее перспективным материалом для изделий из арболитобетона является композиционное гипсовое вяжущее (КГВ). Композиты на основе гипса имеют хорошее сцепление органического заполнителя с вяжущим, прочностные показатели удовлетворительны, распалубочная прочность достигается через 3-5 ч. (в зависимости от марки гипса, сроков схватывания, водогипсового отношения), проблемы с сахарами для этого вида вяжущего не так актуальны. После твердения композит на гипсе характеризуется относительно невысокой влажностью. Добавками, которые предположительно могут улучшать свойства композиционного гипсового вяжущего, является микрокремнезем и высокоактивный метакаолин, которые могут выполнять роль пуццолановых добавок для композиционного гипсового вяжущего. Подбор состава строительной смеси на основе композиционного гипсового вяжущего (КГВ) для арболитобетона и регулирование физико-механических свойств выполнялись путем введения этих добавок.

Исследование физико-механических характеристик КГВ. Исследовано влияние на прочность при сжатии, прочность при изгибе, водостойкость, плотность КГВ высокоактивного метакаолина (ВМК) и микрокремнезема и проведен сравнительный анализ влияния этих добавок на свойства КГВ. Результаты представлены на рисунке 1.

Как видно из диаграмм, использование высокоактивного метакаолина в составе КГВ по сравнению с микрокремнеземом дает значительный прирост ряда свойств: на 20 \% повышается прочность при сжатии, на 18 \% прочность при изгибе, в пределах 
8-10 \% - водостойкость. Плотность составов на высокоактивном метакаолине на 18 \% выше, чем составов с микрокремнеземом. Водостойкость полученного композиционного гипсового вяжущего составила 0,89-0,9, что в 2 раза выше водостойкости гипса.

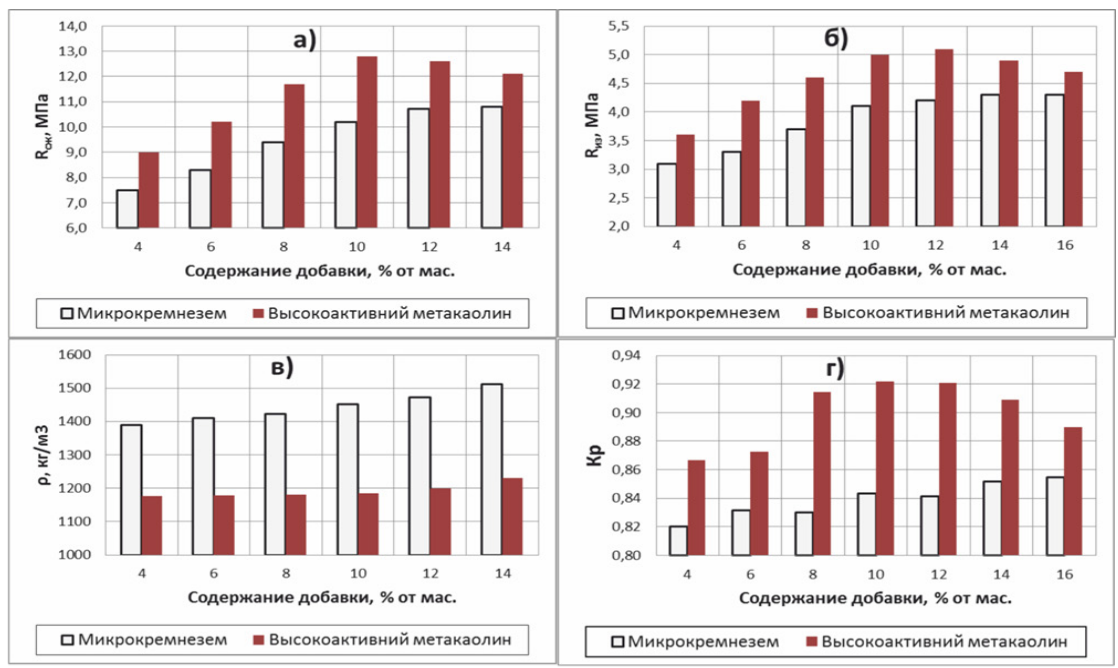

Рисунок 1. Аиаграммы влияния пуццолановых добавок на свойства композиционного гипсового вяжущего

Исследование физико-механических свойств органического заполнителя. Целлюлозосодержащие заполнители растительного происхождения оказывают существенное влияние на процессы структурообразования, физико-механические и эксплуатационно-строительные свойства арболитобетона. Из-за сравнительно высокой проницаемости органический целлюлозный заполнитель обладает большим водопоглощением, чем любой минеральный пористый. Этому способствует соответствующая структура частиц (рисунок 2). 

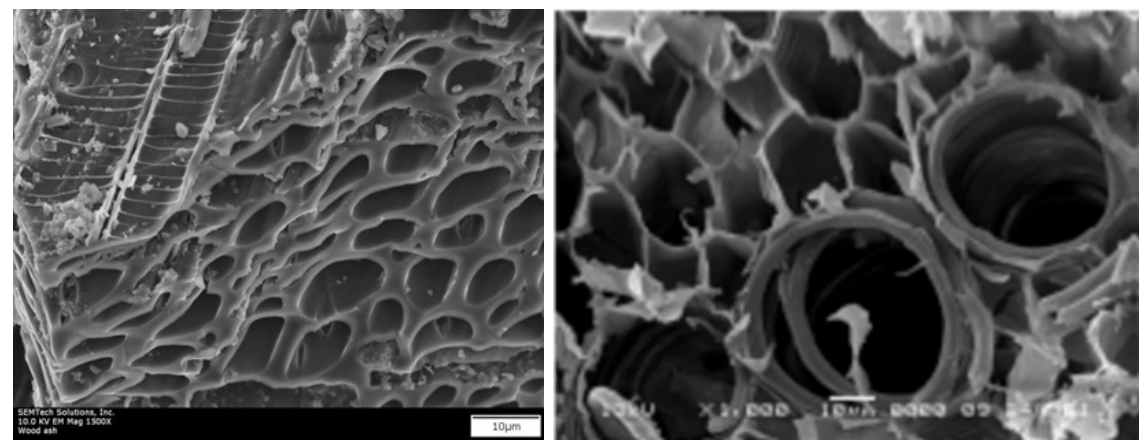

Рисунок 2. Микрофотографии частиц Аревесины (слева), костры конопли (справа)

При приготовлении арболитовой смеси рекомендуется поддерживать высокие значения В/Ц (1-1,3) [3], а это ведет к снижению прочности материала на композиционном гипсовом вяжущем. Наличие влаги в целлюлозосодержащем заполнителе и влажностные деформации отрицательно влияют на процессы структурообразования арболита, поэтому для получения арболита со стабильными физико-механическими показателями необходимо стабилизировать объем целлюлозосодержащего заполнителя.

На рисунке 3 представлены результаты подбора оптимального соотношения компонентов в системе «вяжущее - органический заполнитель».
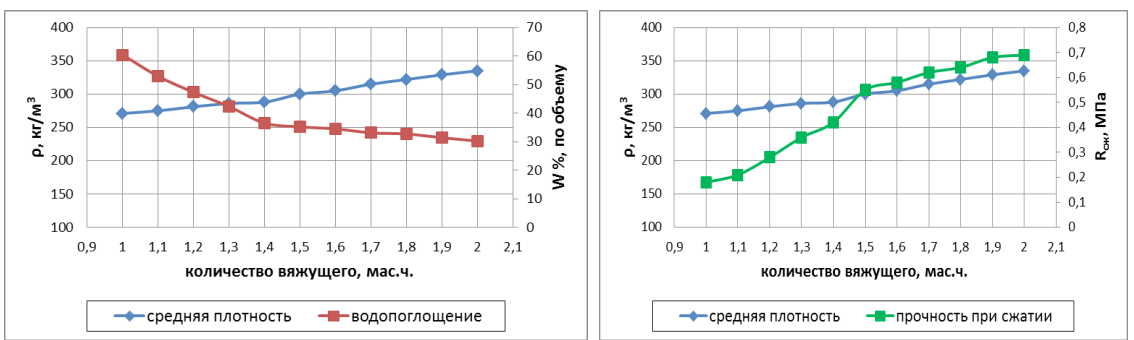

Рисунок 3. Изменения физико-механических свойств арболитобетона в зависимости от содержания вяжущего по отношению к содержанию органического заполнителя 
При содержании вяжущего в смеси от 1,4 до 2 ощутимо уменьшается водопоглощение по объему - до 30 \%. Таким образом, увеличивая количество вяжущего в составе арболитобетона, можно регулировать водопоглощение арболитобетона. Прочность при этом изменяется в 1,7 раз. Для последующих этапов работы взято соотношение компонентов в системе «органический заполнитель - вяжущее» 1:1,5, которое обеспечит получение арболитобетона плотностью менее 400 кг $/ \mathrm{M}^{3}$.

Повышение биостойкости арболитобетона. На следующем этапе исследования проведен анализ возможности повышения биостойкости арболитобетона на композиционном гипсовом вяжущем нанодобавкой высокоактивного пирогенного микрокремнезема, модифицированного соединениями серебра, меди и цинка. На рисунке 4 представленны образцы арболитобетона, изготовленные без использования нанодобавки и с использованием нанодобавки при различном увеличении.
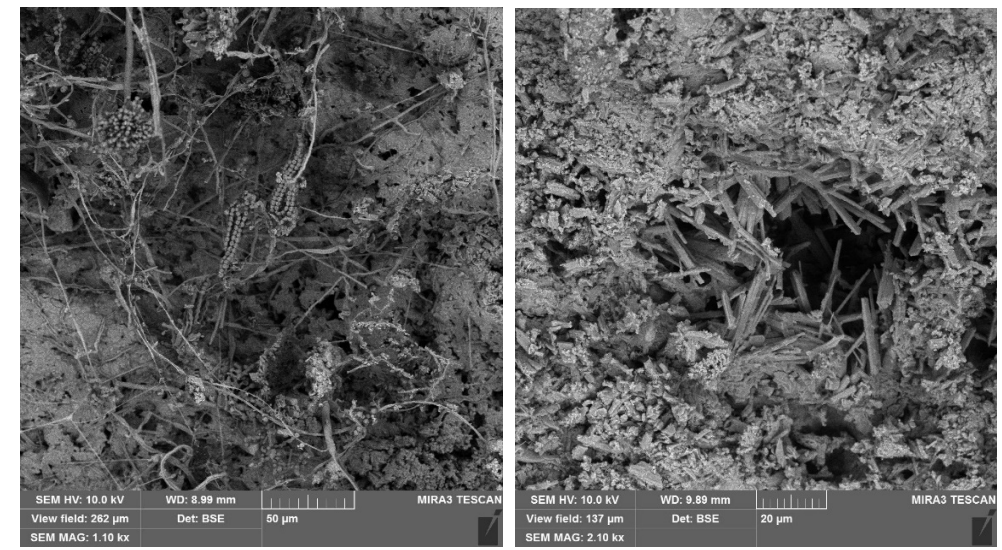

Рисунок 4. Образцы арболитобетона, изготовленные без использования нанодобавки (справа) и с использованием нанодобавки (слева)

Высокодисперсный кремнезем широко используется в качестве неорганического наноразмерного компонента полимерных, органических и неорганических композитов [11]. Высокоразвитая поверхность и особенное строение пирогенного кремнезема позволяют использовать его в качестве матрицы для формирования 
наноразмерных металлооксидных, углеродных и металлических структур (нанодобавок), используя методы химического модифицирования поверхности $[11,12]$.

В работе использовался высокоактивный пирогенный кремнезем, модифицированный соединениями серебра, меди и цинка. Исследованы основные характеристики арболитобетона на антимикробную активность в отношении тест-штаммов некоторых микроорганизмов.

Антибактериальная активность препаратов в отношении тестштаммов показала, что в ряду кремнеземистых нанкомпозиций с различным содержанием металлического серебра активность возрастает в последовательности $10 \%>2 \%>5$ \%. Поэтому для использования в арболитобетоне были рекомендованы нанокомпозиции с 10-процентным содержанием серебра от содержания высокоактивного пирогенного кремнезема.

Подбор фракционного состава органического заполнителя. Эксперимент по подбору фракционного состава органического заполнителя поставлен по симплекс-решетчатому плану Шеффе для смесей [13-14]. Расчет экспериментально-статистических (ЭС) моделей и визуализация графической части выполнены в программе STATISTICA с ошибкой, не превышающей 2,7 \%. В эксперименте варьировалось три независимых фактора - фракции органического заполнителя размером 10-20мм (X), 5-10мм (Y), 2,5-5мм (Z). Фракции органического заполнителя более 20 мм и менее 2,5 мм не анализировались в силу их незначительного нормированного содержания в заполнителе. Оценка фракционного состава органического заполнителя определялась по показателям частных остатков на ситах в соответствии со стандартом [8].

В результате реализации эксперимента получены трехфакторные смесевые ЭС-модели, описывающие изменение прочности при сжатии и плотности под влиянием фракционного состава заполителя. Зависимость прочности на сжатие от соотношения количества разных фракций органического заполнителя описывается ЭС-моделью (1):

$$
\begin{gathered}
\ln \left\{\mathrm{R}_{\text {сж }}\right\}=2,69 * \mathrm{x}+3,12 * \mathrm{y}+3,15 * \mathrm{z}+0.002 * \mathrm{x} * \mathrm{y}+ \\
+0.004 * \mathrm{x} * \mathrm{z}-0.00 * \mathrm{y} * \mathrm{z}+0,001 * \mathrm{x} * \mathrm{y} * \mathrm{z} ;
\end{gathered}
$$


Зависимость плотности от соотношения количества разных фракций органического заполнителя описывается ЭС-моделью (2):

$$
\begin{gathered}
\ln \{\rho\}=0,05 * x+0,05 * y+0,04 * z-0,0004 * x * y-0,0005 * x * \\
z-0,0006 * y * z+0,0004 * x * y * z ;
\end{gathered}
$$

a)

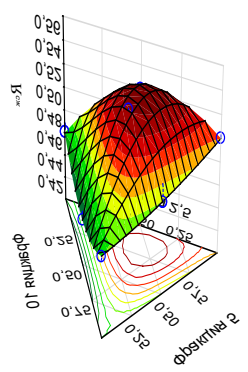

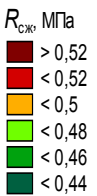

б)

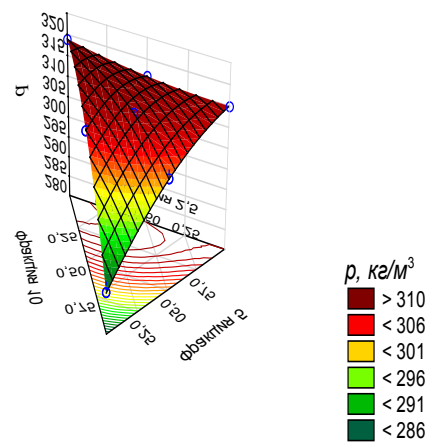

Рисунок 5. Влияние фракционного состава органического заполнителя на прочность при сжатии плотность арболитобетона на КГВ

По ЭС-моделям (1) и (2) проанализировано влияние фракционного состава органического заполнителя на свойства арболитобетона на композиционном гипсовом вяжущем. Оценка влияния каждого фактора (фракция органического наполнителя) на соответствующее значение свойств (прочность при сжатии, плотность) выполнялась по построенным диаграммам, представленным на рисунке 5.

Как видно из диаграмм на рисунке 5, область оптимальных фракционных составов, которые обеспечивают заданные показатели по прочности (класс прочности В0,35 и выше) для КГВ, значительно шире области в рекомендуемых ДСТУ пределах. Рекомендуемые фракционные составы на основе КГВ обеспечивают получение арболитобетона плотностью 300 кг/м ${ }^{3}$, что значительно ниже рекомендованных ДСТУ [8] значений плотности для арболитобетона, удовлетворяющего классу по прочности В0,35. 
Оптимизация фракционного состава арболитобетона. Результаты оптимизации фракционного состава органического заполнителя проиллюстрированы на треугольной диаграмме (рисунок 6).

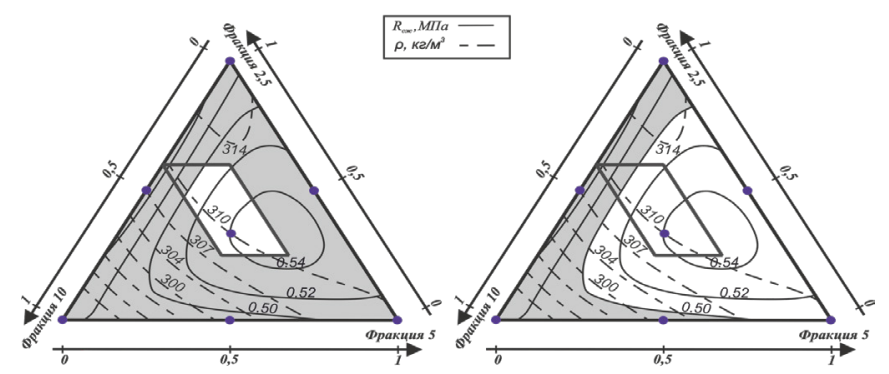

Рисунок 6. Аиаграмма области расположения фракционного состава в рекомендованных по АСТУ пределах и оптимизации фракционного состава органического заполнителя Аля арболитобетона

На диаграмме выделена область составов заданной прочности и пониженной плотности 300 кг $/ \mathrm{M}^{3}$ с учетом состава композиционного гипсового вяжущего, фракционного состава костры и соотношения компонентов в системе «вяжущее органический заполнитель». Оптимальные составы обеспечивают прочность $\mathrm{R}_{\text {сж }} \geq 0,5$ МПа и выше, плотностью $\rho=300$ кг $/ \mathrm{M}^{3}$, что значительно ниже рекомендованных ДСТУ [8] значений плотности для арболитобетона, удовлетворяющего классу по прочности В0,35. Область составов арболитобетона полностью соответствует требованиям ДСТУ, обеспечивая при этом получение арболитобетона с улучшенными свойствами.

Область составов арболитобетона ограничена относительно небольшой зоной на графике в рекомендуемых по ДСТУ пределах [8] для фракций органического заполнителя, что существенно ограничивает количество вариантов по подбору состава при регулировании свойств изделия. Как видно из диаграмм, существенное влияние на свойства арболитобетона оказывает содержание фракции 5-10 мм. Увеличение содержания этой фракции в составе органического заполнителя возможно с 40-60 \% по сравнению с нормами ДСТУ. Оптимальные составы обеспечивают класс прочности В0,35 и В0,5 плотностью 300- 
$312 \mathrm{\kappa г} / \mathrm{M}^{3}$, что ниже нормированных значений плотности 400450 кг $/ \mathrm{M}^{3}$ для указанных классов по прочностидля арболитобетона.

\section{ЗАКАЮЧЕНИЕ}

Как показали результаты наших исследований, в частности фракционный состав органического заполнителя на костре конопли может быть скорректирован по отношению к составам на древесной щепе. Область составов арболитобетона ограничена относительно небольшой зоной на графике (рисунок 6) в рекомендуемых по ДСТУ пределах [8] для фракций органического заполнителя, что существенно ограничиваетколичествовариантов по подбору состава при регулировании свойств изделия. Как видно из диаграмм, существенное влияние на свойства арболитобетона оказывает содержание фракции 5-10 мм. Увеличение содержания этой фракции в составе органического заполнителя возможно с 40-60 \% по сравнению с нормами ДСТУ.

Исходя из изложенного, имеет место расширение области выбора составов за границы рекомендуемого стандартом фракционного состава органического заполнителя, если при этом получаемые изделия соответствуют требуемому классу по прочности.

\section{СПИСОК ИСПОЛЬЗОВАННЫХ ИСТОЧНИКОВ}

1. Шинкевич, E. С. Возможности арболитобетона. Исследования одесских ученых / Е. С. Шинкевич, Д. С. Линник, В. И. Юсипчук // Будівельний журнал. Інформаційно-аналітичний журнал. - 2018. - № 5-6 (135-136). - С. 33.

2. Котенко, В. Д. Композиционные материалы из древесины: современные тенденции развития / В. Д. Котенко // Вестник МГЛУ. - 2000. - № 1. - С. 50-52.

3. Наназашвили, И. Х. Строительные материалы из древесноцементной композиции / И. Х. Наназашвили; 2-е изд., перераб. и доп. - Л. : Будиздат, 1990. - 415 с. 
4. Stevulova, N. Lightweight Composites Containing Hemp Hurds / N. Stevulova, L. Kidalova // Procidea engineering. - 2013. No. 65. - pp. 69-74.

5. Kidalova, L. Effective utilization of alternative materials in lightweight composites / L. Kidalova, N. Stevulova, E. Terpakova, M. Helcman // Chem. Eng. Transac. - 2011. - No. 25. pp. 1079-1084.

6. Ashori, A. Bio-based composites from waste agricultural residues / A. Ashori, A. Nourbakhsh // Waste Management. 2010. - No. 30. - 680 p.

7. Bledzki, AK. Composites reinforced with cellulose base fibres / AK. Bledzki, J. Gassan // Progr. Polym. Sci. - 1999. - No. 24. pp. 221-274.

8. Арболіт та вироби 3 нього. Загальні технічні умови : ДСТУ Б В.2.7-271:2011. - УК НД 91.100.99 - Введено вперше (зі скасуванням в Україні ГОСТ 19222-84). ДП «Укрархбудінформ», 2012. - 32 с.

9. Шинкевич, Е. С. Экостроительство из арболитобетона на основе композиционного гипсового вяжущего / Е. С. Шинкевич, Д. С. Линник, В. И. Юсипчук // Строительные материалы, изделия и санитарная техника: науч.-техн. сб. - 2014. - Вып. 52. - С. 112-116.

10. Линник, Д. С. Влияние высокоактивной пуццолановой добавки на свойства композиционного гипсового вяжущего и арболитобетона на его основе / Д. С. Линник, В. И. Юсипчук, Е. С. Шинкевич // Вісник ОДАБА. - 2015. Вип. 57. - С. 273-278.

11. Богатырев, В. M. Нанокомпозиты $\mathrm{MxOy/SiO} 2$ на основе ацетатов $\mathrm{Ni}, \mathrm{Mn}, \mathrm{Cu}, \mathrm{Zn}, \mathrm{Mg}$ / В. М. Богатырев, Л. И. Борисенко, Е. И. Оранская, М. В. Галабурда // Химия, физика и технология поверхности : Межведомсвт. сб. науч. тр. - Киев, 2009. - Вып. 15. - С. 294-302.

12. Богатырев, В. М. Исследование влияния добавок на скорость гидратации оксида кальция методом рентгенофазного анализа / В. М. Богатырев, Л. И. Борисенко, В. И. Юсипчук // Поверхность : сб. науч. тр. / Ин-т химии поверхности НАНУ. - Киев, 2014. - Вып. 6(21). - С. 123-128. 
13. ЭВМ и оптимизация композиционных материалов / В. А. Вознесенский [и др.]. - Киев : Будивельник, 1989. $240 \mathrm{c}$.

14. Шинкевич, Е. С. Оптимизация составов сухих строительных смесей на основе экспериментально-статистических моделей / Е. С. Шинкевич, Е. Б. Тымняк, Д. С. Линник, А. А. Тертычный // Строительные материалы, изделия и санитарная техника: науч.-техн. сб. - 2013. - Вып. 48. C. 179-183.

Статья поступила: 15.11.2019

\section{REFERENCES}

1. Shinkevich E. S., Linnik D. S., Yusipchuk V. I. Budivelnij zhurnal. Informacijno-analitichnij zhurnal. 2018. No. 5-6 (135136). P. 33. (rus)

2. Kotenko V. D. Forestry bulletin. 2000. No 1. pp. 50-52. (rus)

3. Nanazashvili I. H. Stroitelnye materialy iz drevesno-cementnoj kompozicii [Building materials from wood-cement composition]. Leningrad: Budizdat, 1990. 415 p. (rus)

4. Stevulova N., Kidalova L. Procidea engineering. 2013. No. 65. pp. 69-74. (en)

5. Kidalova L., Stevulova N., Terpakova E., Helcman M. Chem. Eng. Transac. 2011. No. 25. pp. 1079-1084. (en)

6. Ashori A., Nourbakhsh A. Waste Management. 2010. No. 30. 680 p. (en)

7. Bledzki AK., Gassan J. Progr. Polym. Sci.1999. No. 24. pp. 221274. (en)

8. Arbolit ta virobi z nogo. Zagalni tehnichni umovi [Arbolite and articles thereof. General specifications]: DSTU B V.2.7271:2011. DP «Ukrarhbudinform», 2012. 32 p. (ukr)

9. Shinkevich E. S., Linnik D. S., Yusipchuk V. I. Stroitelnye materialy, izdeliya i sanitarnaya tehnika. 2014. No. 52. pp. 112-116. (rus)

10. Linnik D. S. Shinkevich E. S., Yusipchuk V. I. Vesnik OGASA. 2015. No. 57. pp. 273-278. (rus) 
11. Bogatyrev B. M., Borisenko L. I., Oranskaya E. I., Galaburda M. V. Himiya, fizika i tekhnologiya poverkhnosti. 2009. No. 15. pp. 294-302. (rus)

12. Bogatyrev B. M., Borisenko L. I., Yusipchuk V. I. Poverkhnost. 2014. No. 6(21). pp. 123-128. (rus)

13. Voznesenskiy V. A., Lyashenko T. V., Ivanov Ya. P. EVM $i$ optimizaciya kompozicionnyh materialov [Computers and optimization of composite materials]. Kiev: Budivelnik, 1989. 240 p. (rus)

14. Shinkevich A. S., Tymnyak E. B., Linnik D. S., Tertychnyy A. A. Stroitelnyye materialy, izdeliya i sanitarnaya tekhnika. 2013. No. 48. pp. 179-183. (rus)

Received: 15.11.2019 